\title{
A ARCA DE NOÉ PÓS-MODERNA NA PANDEMIA DA COVID-19: UMA ANÁLISE ATRAVÉS DO DIREITO DOS DESASTRES
}

The Pos-Modern Noah's Ark In Covid-19 Pandemic: An Analysis Through Disaster Law

\section{Francielle Benini Agne Tybusch}

Universidade Federal de Santa Maria (UFSM), Santa Maria, RS, Brasil

Lattes: http://lattes.cnpq.br/4400702817251869 Orcid: https://orcid.org/0000-0001-6158-399X

E-mail:francielleagne@gmail.com

\section{Jerônimo Siqueira Tybusch}

Universidade Federal de Santa Maria (UFSM) , Santa Maria, RS, Brasil

Lattes: http://lattes.cnpq.br/6477064173761427 Orcid: https://orcid.org/0000-0001-8238-7453

E-mail:eronimotybusch@ufsm.br

\section{Francieli lung Izolani}

Universidade Federal de Santa Maria (UFSM), Santa Maria, RS, Brasil

Lattes: http://lattes.cnpq.br/9027530784430798 Orcid: https://orcid.org/0000-0002-1307-7758

E-mail:franizolani@hotmail.com

Trabalho enviado em 08 de setembro de 2020 e aceito em 07 de junho de 2021

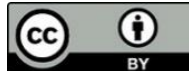

This work is licensed under a Creative Commons Attribution 4.0 International License.

Rev. Dir. Cid., Rio de Janeiro, Vol. 14, N.01., 2022, p. 170-193.

Francielle Benini Agne Tybusch, Jerônimo Siqueira Tybusch e Francieli lung Izolani 


\section{RESUMO}

A pandemia da COVID-19 pode ser considerada um desastre biológico advindo da má gestão de riscos pela sociedade pós-moderna, revelando as mais variadas vulnerabilidades socioambientais, na medida em que não atinge a todos equitativamente. Ademais, promove a seleção de serviços considerados essenciais e pessoas para serem protegidas e outras para serem sacrificadas em prol da coletividade, como uma Arca de Noé, agora, pós-moderna. Objetivo: Nesse contexto, por estarem intrinsicamente relacionadas vulnerabilidades e gestão de riscos, objeto de estudo da Teoria do Direito dos Desastres, o presente artigo tem por objetivo analisar quais as possibilidades de aplicação desta Teoria na pandemia da COVID-19. Método: Para tanto, foi utilizado o quadrinômio metodológico, tendo como teoria de base, a Teoria do Direito dos Desastres, de Délton Winter de Carvalho e Daniel Faber, como método de abordagem, a opção pela sistêmico-complexa, cotejada em Fritjof Capra e em Edgar Morin, como método de procedimento a análise bibliográfica, a partir das técnicas de fichamentos e resumos. Resultados e contribuições: Conclui-se pela possibilidade de aplicação da Teoria do Direito dos Desastres, especificamente, a gestão socioambiental do risco à pandemia da COVID-19, identificando esta enquanto desastre biológico.

Palavras-chave: COVID-19. Desastre biológico. Gestão de riscos. Teoria do Direito dos Desastres. Vulnerabilidade.

\section{ABSTRACT}

COVID-19 pandemic can be considered a biological disaster that has come from the bad risk management by the postmodern society, showing the most varied socio-environmental vulnerabilities, considering that it has not reached everybody equally. Furthermore, it has promoted the selection of service considered essential as well people to be protected while others to be sacrificed for the community benefit, such as a Noah's Ark, now, a postmodern one. Goal: In this context, due to the intrinsic relation between vulnerabilities and risk management, the Theory of Disaster Law's object of study, this paper aims to analyze what the possibilities to apply that Theory in the COVID-19 pandemic are. Method: For that, the methodological quadrinomial was used, having as basic theory the Theory of Disaster Law, of Daniel Faber and Délton Winter de Carvalho, as the method of approach, the option 
for the systemic-complex one, boarded by Fritjof Capra and Edgar Morin, as a procedure method the bibliographic analysis, based on the file and abstract techniques. Conclusions and contributions: It concluded by the possibility of applying the Disaster Law Theory, specially, the socioenvironmental management of risk for COVID-19, identifying itself as a biological disaster.

Keywords: COVID-19. Biological disaster. Risk management. Theory of Disaster Law. Vulnerability.

\section{INTRODUÇÃO}

Os desastres revelam as vulnerabilidades socioambientais, impactando as pessoas e as suas mais diversas relações de diferentes formas e intensidades de acordo com a sua posição do lado de cá ou do lado de lá da linha imaginária ${ }^{1}$ que divide esta sociedade pós-moderna. A pandemia da COVID19 pode ser considerada um desastre na medida em que é causada pelo próprio sistema social posto e que tem como consequências impactos irreversíveis aos mais diversos sistemas existentes, como o ambiental, o econômico, o científico e o político, demonstrando as vulnerabilidades em suas mais diversas dimensões, encontrando-se a social como aquela em que o direito deve buscar exercer sua prioridade.

Nesse sentido, no que se refere a esses diferentes impactos sobre a sociedade, a COVID-19 ressignifica a história da Arca de Noé, considerando-a agora, uma Arca de Noé pós-moderna, na medida em que os riscos e os impactos causados ante à vulnerabilidade socioambiental posta passa a selecionar indivíduos ou famílias inteiras para sobreviverem e outras para se sacrificarem em prol de outros membros da sociedade que possuam "maior valor" ou que, então, mereçam maior proteção devido à suas melhores condições socioeconômicas.

Dessa forma, em uma sociedade de risco como é a atual, desastres não necessariamente são sofridos pelos seus criadores, tampouco são suportados de forma igualitária por todos frente às desigualdades multidimensionais existentes. Outrossim, é com base em discursos persuasivos de poder que determinados locais são classificados de essenciais, ficando abertos inclusive diante da

\footnotetext{
${ }^{1}$ Em referência às linhas que dividem o mundo em ricos e em pobres, com relação a hegemonias alertadas por Boaventura de Sousa Santos em seu artigo Para Além do Pensamento Abissal: das linhas globais a uma ecologia de saberes. In: SANTOS, Boaventura de Sousa; MENESES, Maria Paula (Org.). Epistemologias do Sul. São Paulo: Cortez, 2010. p. 31-83.
} 
medida preventiva de isolamento social, bem como profissionais de determinadas áreas são escolhidos para continuarem, supostamente, promovendo o bem-estar geral da população.

Todavia, a questão da vulnerabilidade socioambiental frente a desastres deve ser enfrentada de forma mais profunda, considerando as multidimensões da desigualdade em que a pandemia surte efeitos, partindo, inclusive, da discussão sobre riscos gerados e riscos experimentados, questões de colonialidade da sociedade localizada do lado de cá da linha, voltada para atender a interesses hegemônicos e, não menos que o próprio sistema capitalista a partir de um processo complexo de globalização que passa a configurar novas vulnerabilidades a determinadas pessoas, estando a social e a ambiental implícitas.

Assim, considerando que desastres atingem sistemicamente a sociedade e que são fatores determinantes de avivar as vulnerabilidades, intimamente relacionados com a gestão de riscos, por sua vez, objeto de estudo da Teoria do Direito dos Desastres, o presente artigo tem como problema central analisar quais as possibilidades de aplicação desta Teoria na pandemia da COVID-19.

A metodologia utilizada obedece ao quadrinômio, teoria de base, abordagem, procedimento e técnica. Como teoria de base, foi amparada na Teoria do Direito dos Desastres, de Daniel Farber e Délton Winter de Carvalho, através de uma reflexão sobre o papel do Direito na gestão de riscos. Já, como método de abordagem, a opção pela sistêmico-complexa, cotejada em Fritjof Capra e em Edgar Morin, a partir da inflexão que a pandemia da COVID-19 espraia-se em diversos sistemas interconectados, quais sejam direito, política, ecologia, economia, ao mesmo passo que possui complexidade atinente às questões socioambientais às quais está imersa, como a variabilidade de impacto nas diversas camadas da sociedade e suas relações na busca e capacidade de superação deste novo paradigma. Ademais, com relação ao método de procedimento foi a análise bibliográfica a opção, a partir da leitura de doutrinas e artigos científicos, tendo como técnicas os fichamentos e resumos.

Para tanto, o presente artigo foi dividido em dois itens temáticos. O primeiro teve por escopo compreender os impactos da COVID-19 sobre a vulnerabilidade socioambiental, a partir do entendimento de que risco e vulnerabilidade afetam desigualmente as pessoas. O segundo e último item teve por objetivo identificar as possibilidades de aplicação da Teoria do Direito dos Desastres à COVID-19. 


\section{RISCO E VULNERABILIDADE SOCIOAMBIENTAL NA PANDEMIA DA COVID-19: REFLEXOS DE UMA DESIGUALDADE SISTÊMICO-COMPLEXA}

A vulnerabilidade socioambiental, cuja estreita relação dá-se com o nível de desenvolvimento de um país, é temática que vem sendo discutida desde a Rio +20 , a Conferência das Nações Unidas para o Desenvolvimento Sustentável, ocorrida na cidade do Rio de Janeiro em 2012. A combinação de processos sociais relacionados a direitos sociais como trabalho, renda, saúde, educação, saneamento, com as mudanças ambientais resultantes da degradação de áreas de proteção ocupadas pelo homem, desmatamento, poluição e superexploração de recursos naturais, resulta na vulnerabilidade socioambiental, atrelando condições de vida precárias e ambientes deteriorados que, por sua vez, revelam a menor capacidade de redução de riscos (FREITAS et al, 2012).

A partir dessa concepção, pode ser destacado o caráter sistêmico-complexo da vulnerabilidade em questão. Sistêmico, porque o todo é formado para além da soma de partes que a compõem, considerando as interações e as inter-relações entre as partes, em uma visão mais ecológica e consciente de que tudo faz parte de uma teia da vida (CAPRA, 2012). A própria questão socioambiental, nesse sentido, envolve vários sistemas, econômico, cultural, social, ambiental, ético, dentre outros, encontrando-se a possibilidade de uma compreensão a partir de cada um deles, mas que, sem seu entrelaçamento, não há que se falar em entendimento plausível. Portanto, Capra (2012) reforça que ao ser dado ênfase nas partes apenas, se está diante de uma visão reducionista e mecanicista, ao passo que a ênfase no todo revela a visão ecológica.

Outrossim, trata-se de questão complexa à medida que há a sensatez para a percepção de diferentes níveis de complexidade dentro de cada sistema, complementando a ideia do pensamento sistêmico. Ainda, segundo Capra (2012), a temática ecológica envolve comunidade e rede, cujas relações entre seus organismos são mútuas e entrelaçadas, constituindo-se ao mesmo tempo em pequenos conjuntos complexos nos quais as totalidades integradas possuem propriedades essenciais a partir de interações e interdependência entre suas partes.

Quando questões socioambientais se encontram em foco, há a necessidade de serem visualizadas através de sua complexidade, apontando para o que Edgar Morin (2003) chama de uma tomada de consciência por um novo modo de organização do saber e atentando para o fato de que ameaças graves a todas as espécies, causadas pelo desequilíbrio ecológico, estão ligadas ao progresso 
cego e descontrolado do conhecimento, bem como de padrões mutilados que dificultam o entendimento da realidade.

O problema da vulnerabilidade envolve riscos e entrelaçamento de fenômenos sociais, econômicos, culturais, éticos e pode também ser relacionado à falta das multidimensões da sustentabilidade, seja em Ignacy Sachs (2004) e suas oito dimensões, em Juarez Freitas (2012) e suas cinco dimensões, ou ainda, na falta do pensamento voltado a uma sustentabilidade pós-colonial, conforme preconiza Jerônimo Siqueira Tybusch (2011). A pobreza, especialmente, mais acentuada em países do chamado Sul Social ${ }^{2}$, terminologia usada por Boaventura de Sousa Santos (2016), denota a dificuldade para a superação de desastres, bem como para a prevenção de riscos, considerando que sequer possuem direitos básicos garantidos, sofrendo ainda mais com os padrões assumidos pela sociedade global e o descontrole causado por esta sociedade de risco (GIDDENS, 2003), que busca incessantemente o atendimento das demandas hegemônicas, tendendo para o colapso.

Portanto, a vulnerabilidade socioambiental é causa e consequência de processos humanos produzidos e espraiados em diferentes níveis dentro da era mecanicista em que a humanidade, ou a falta de humanidade, vive. Não há como compreender os problemas dela decorrentes sem buscar as relações complexas a partir, essencialmente, da globalização e da forma moderna desenvolvimentista que se busca enquanto parâmetro.

Feito esse breve aporte sobre a complexidade-sistêmica das questões ambientais, em amplo aspecto, na atualidade, mais uma prova materializada do mundo em descontrole e de todas as mazelas da vulnerabilidade socioambiental existente no Sul Social, é a pandemia da COVID-19, causada por um novo coronavírus (SARS-CoV-2), identificado em Wuhan na China, podendo variar de um resfriado comum para a Síndrome Respiratória do Oriente Médio e para a Síndrome Respiratória Aguda Grave (MINISTÉRIO DA SAÚDE, 2020).

\footnotetext{
${ }^{2}$ De acordo com Boaventura de Sousa Santos e Maria Paula Meneses, "o Sul é aqui concebido como um campo de desafios sistêmicos, que procuram reparar os danos e impactos historicamente causados pelo capitalismo na sua relação colonial com o mundo. Esta concepção do Sul sobrepõe-se em parte com o Sul geográfico, o conjunto de países e regiões do mundo que foram submetidos ao colonialismo europeu e que, com exceções como, por exemplo, da Austrália e da Nova Zelândia, não atingiram níveis de desenvolvimento econômico semelhantes ao Norte global (Europa e América do Norte). A sobreposição não é total porque, por um lado, no interior do Norte geográfico classes e grupos sociais muito vastos (trabalhadores, mulheres, indígenas, afrodescendentes, muçulmanos) foram sujeitos à dominação capitalista e colonial, e por outro lado, porque no interior do Sul geográfico houve sempre as 'pequenas Europas', pequenas elites locais que beneficiaram da dominação capitalista e colonial e que depois das independências a exerceram e continuam exercer, por suas próprias mãos, contra classes e grupos subordinados". (SANTOS; MENESES; NUNES, 2010, p. 19).
} 
A pandemia da COVID-19 é um desastre global constituído socialmente em decorrência da dinâmica de desenvolvimento socioeconômico da atualidade, e do descuido com a proteção ambiental, o que vem a acentuar as consequências quanto maior for a vulnerabilidade socioambiental, apontando para a ausência de capacidade de redução do risco. Outros exemplos ocorridos em países pobres, como o terremoto do Haiti em 2010 ou como o deslizamento de terra na região serrana do Rio de Janeiro em 2011, também demonstraram que a situação político, econômica, social e ambiental estabelecidas antes dos eventos fatídicos eram bastante precárias (FREITAS et al, 2012). 0 ciclo da pobreza alimenta e retroalimenta o da degradação ambiental, revelando a alta vulnerabilidade socioambiental e o agravamento das consequências dos próprios desastres, em um ciclo vicioso de crise.

Eventos como esses e o da pandemia atual encontram-se intimamente relacionados com a degradação ambiental, pois quanto mais pobre for o local, haverá o aumento da vulnerabilidade socioambiental, que será, por sua vez, convertida em desastres, afetando os mais pobres de modo mais intenso. $\mathrm{O}$ novo mundo moldado por tecnologias, estruturas sociais padronizadas, globalização econômica gera uma desintegração social, uma deterioração mais intensa do meio ambiente e aponta para a disseminação de novas doenças e de uma pobreza cada vez maior (CAPRA, 2002).

Ademais, o padrão capitalista globalizado incrementa cada vez mais a pobreza, a desigualdade e a exclusão social que, em tempos de pandemia, tornam-se ainda mais evidentes, a ponto de existir um Quarto Mundo, "povoado por milhões de pessoas que não têm onde morar nem o que comer [...], passando em sua vida por crises múltiplas [...] e no momento em que a sua pobreza transforma-se em miséria, essas pessoas facilmente se veem presas em um espiral descendente de marginalidade." (CAPRA, 2002, p. 156).

É o que a pandemia da Covid-19 ressalta: o Quarto Mundo, ou mundo da vulnerabilidade socioambiental, escolhido para se sacrificar por todos, estando na informalidade ou nos postos de trabalho considerados, agora, essenciais, prescindindo ao isolamento social, tão propagado como a medida eficaz para evitar a disseminação do vírus e o aumento das mortes. Assim, fica evidente que o chamado crescimento econômico global não fez diminuir a pobreza e, não, não estão todos no mesmo barco diante da pandemia. Não houve e nem haverá um crescimento econômico contínuo e indiferenciado em todo o globo, os impactos desse padrão de exploração da natureza trarão desastres dos mais variados, com os impactos mais severos sobre os mais pobres e vulneráveis deste sistema insustentável multidimensionalmente. 
Como bem afirma Boaventura de Sousa Santos (2020), a vulnerabilidade que precede a quarentena é agravada com ela, já que esta é sempre discriminatória, afetando grupos específicos, como as mulheres, os trabalhadores precários, os informais, os supostamente autônomos, os trabalhadores de rua, os sem-abrigo, os refugiados, os deficientes, os idosos, os presos, os moradores das periferias, sendo que estes últimos correspondem à cerca de 1,6 milhões de pessoas sem habitação adequada, sem condições básicas de saneamento, inclusive.

A partir dessa contextualização sobre os vulneráveis ante à pandemia, é possível visualizar a Arca de Noé Pós-Moderna, visto que a Covid-19 discrimina os vulneráveis quanto à sua prevenção, expansão e mitigação. A discriminação vai desde aqueles escolhidos para trabalhar em condições de risco, perpassa pelos escolhidos para morrerem porque já viveram o bastante e também atinge os que precisam sustentar a si e a sua família, mas que sequer dispõe de água potável e sabão para higienizar as mãos, nem a imprescindível máscara.

Não é somente esta pandemia, é a dengue, a febre amarela, a malária, e todas as mazelas que sobrevivem para a coexistência da Arca, garantindo a sobrevivência dos que socialmente importam, dos que conseguem \#ficaremcasa, porque possuem condições socioeconômicas de se protegerem das adversidades e, em uma eventualidade, encontrarão seu leito hospitalar privativo e bemsupervisionado, assim como, logo, poderão ter acesso às vacinas fabricadas pelas grandes corporações de medicamentos, que estão a lucrar com a cura dos selecionados para serem curados.

Nesse sentido, destaca Harvey (2020) que as repercussões econômicas e demográficas de disseminação do vírus dependem das vulnerabilidades no modelo econômico hegemônico e, não menos, que há uma nova classe trabalhadora na linha de frente, desprovida de recursos e carecedora de estar na situação de risco, não podendo fazer o isolamento ou colocar-se em quarentena e, portanto, faz com que a Covid-19 configure uma pandemia de classe, gênero e raça.

Há também a questão reacionária ao vírus dos países hegemônicos e a dos países do outro lado da linha abissal. Enquanto os hegemônicos estão lucrando com big data, venda de máscaras a base de nanotecnologia, e outros equipamentos tecnológicos, como a China, demonstrando a sua superioridade diante da pandemia através da reinvenção do próprio capitalismo (HAN, 2020), continuando sua ascensão como potência global hegemônica, considerando-a superior e fornecedora mundial nas áreas farmoquímica, automotriz, aeronáutica, eletrônica e telecomunicações (ZIBECHI, 2020), em países como o Brasil, há crise acentuada pelo vírus na saúde, na segurança, no mercado de trabalho, na economia, o que para Zibechi (2020), supõe o aprofundamento da decadência e da crise para os mais pobres.

Rev. Dir. Cid., Rio de Janeiro, Vol. 14, N.01., 2022, p. 170-193.

Francielle Benini Agne Tybusch, Jerônimo Siqueira Tybusch e Francieli lung Izolani

DOI: $10.12957 /$ rdc.2022.54314| ISSN 2317-7721 
Outros autores, como Maria Galindo (2020), consideram a Covid-19 como o Holocausto do século XXI, pelo fato do extermínio em massa de pessoas ante a lógica darwiniana justificada na falta de um sistema eficaz de saúde, escolhendo aqueles sem utilidade para serem deixados morrer, que foram contaminados pelos turistas portadores de presentes e corpos infectados de países cobiçados para férias e viagens, sendo que as chances de sobrevivência são diversas considerando a vulnerabilidade socioambiental atinente a cada grupo.

Assim, a pandemia, que de acordo com Markus Gabriel (2020) possui origem no grego, significando todo o povo, denota as debilidades da ideologia hegemônica dominante de que o progresso tecnocientífico era o único que impulsionaria o progresso humano, resultando-a como um produto da globalização, a partir do desequilíbrio atinente do embate entre equilíbrio ambiental e economia, sendo esta priorizada em detrimento daquele, como uma conditio sine qua non.

Ocorre que esse processo de globalização, ao contrário da ideologia do progresso e do avanço, disseminada pelo Norte Social como condição ao Sul e, com a ajuda da falta de racionalidade multidimensional, que, por sua vez, causa, a falta de pensamento complexo e a cegueira persuasiva para que padrões homogeneizadores sejam seguidos, causou um desastre de proporções intercontinentais, resultado da produção sistemática de desconsiderar a vida de todos com igual valor e dignidade, fazendo, não obstante, aflorar as mais profundas vulnerabilidades e exclusões, cabendo, outrossim, a busca por soluções sistêmico-complexas.

Dentre essas soluções, a Teoria do Direito dos Desastres que, inicialmente, poderia levar à conclusão de que somente seria aplicável a desastres ocasionados por atividades mineradoras, carece de aprofundamento, fornecendo a amplitude viável, bem como o aporte do pensamento complexo, para que diante de pandemias como a atual, as respostas fossem também complexas e abrangentes. Nesse ponto, passa-se ao próximo item para desvendar se o Direito dos Desastres teria alguma interrelação com a Covid-19, bem como possibilidades de sua aplicação, considerando os riscos ambientais, os conflitos socioambientais e as vulnerabilidades que afetam as populações das mais variadas cidades do planeta, incluso do Brasil.

\section{TEORIA DE DIREITO DOS DESASTRES E INTER-RELAÇÃO COM A COVID-19: POSSIBILIDADES DE APLICAÇÃO}

Em um Estado de Direito, como são muitos países do Globo, e também que caracteriza o Brasil, emerge a responsabilidade de se buscar através do próprio Direito a estabilidade entre conflitos e 
disputas de interesses multidimensionais, como o embate entre a dimensão ambiental e a econômica frente a situações diversas, como forma de garantia do progresso e continuidade da existência de direitos fundamentais. Ocorre que, o progresso é confundido com desenvolvimento econômico e, em nome dele, muitos desastres vêm ocorrendo, como uma condição supostamente inevitável ao desenvolvimento almejado e vazio em si mesmo, a longo prazo.

Os padrões hegemônicos seguidos por países do Sul Social levam à permissão inconteste para que países do Norte superexplorem as riquezas naturais de suas antigas colônias, implementando suas indústrias madeireiras, suas corporações de agronegócio, companhias mineradoras, levando a desastres ambientais de proporções territoriais, como a destruição da Amazônia, rompimento de barragens, êxodo rural, além da marginalização de grande parte da população interna ante ao aumento de conflitos socioambientais.

Para além desses exemplos, como parte do processo de globalização que esta sociedade global vem atravessando desde o século XX, encontra-se o hiperestímulo a padrões de produção e consumo insustentáveis em si, almejando à lucratividade a partir da assunção de riscos necessários, como se os fins justificassem os meios e a cientificidade pudesse solucionar os reflexos ambientais desses objetivos de dominação ocultos intencionalmente.

Todavia, há muitos riscos que já nascem incontroláveis nesse mundo globalizado, como pandemias - inclusa a da Covid-19 - e outros desastres, cabendo ao direito também a tentativa de evita-los, ou de, pelo menos, mitigar as consequências geradas pelos padrões globalizados atuais, encontrando-se dentre uma dessas tentativas o surgimento de uma Teoria, a do Direito dos Desastres, contudo, primeiramente, cabe o entendimento do que se constitui um desastre.

Existem diversas formas e referências para definir o que são desastres. Para Kreps "disasters are non-routine events in societies or their larger subsystems (e.g., regions and communities) that involve conjunctions of physical conditions with social definitions of human harm and social disruption" (KREPS, 2001, p. 3718) $)^{3}$. O autor esclarece que o conceito "eventos rotineiros" vai distinguir os desastres como acontecimentos incomuns das preocupações cotidianas. Com relação a condições físicas e definições sociais significa que cada ser é individualmente necessário e que ambos são coletivamente suficientes para que os desastres ocorram no espaço e no tempo.

\footnotetext{
${ }^{3}$ Tradução nossa: "Desastres são eventos não rotineiros nas sociedades ou em seus subsistemas maiores (por exemplo, regiões e comunidades) que envolvem conjunções de condições físicas com definições sociais de dano humano e perturbação social".
} 
Assim, a designação 'sociedades ou subsistemas maiores' tem o sentido de que o dano humano e a ruptura social do evento devem ter relevância para sistemas sociais maiores, exemplo: a pobreza, fome, doenças e conflitos sociais são preocupações crônicas, de outra sorte, depressões econômicas, epidemias e guerras são desastres; o aquecimento global e a ruptura na camada de ozônio são considerados como perigo ou riscos ambientais. Estas significações indicam o modo como se percebe o desastre: imprevisível, fora de controle e devastador; um evento controlado pelos deuses. Da antiguidade a contemporaneidade, a existência humana tem sido marcada pelos efeitos catastróficos destes eventos, o que se modificou neste espaço de tempo, foi a ideia de que eles eram ligados a razões divinas ${ }^{4}$ e, agora, a ideia de progresso (TYBUSCH, F. 2019, p. 149).

Nesse sentido, pode-se afirmar que a ideia e a ocorrência de catástrofes intrigam as populações há muito tempo. $\mathrm{Na}$ antiguidade, os desastres eram de fato conferidos a razões divinas. Apenas no ano de 1755, quando um terremoto atingiu a cidade de Lisboa, os desastres começaram a ser considerados eventos dissociados dos deuses ${ }^{5}$. Este caso foi considerado como o primeiro desastre moderno, e a partir de então, a população se enxergou como ente transformador do ambiente e assim, passaram a demandar mais do governo (CARVALHO; DAMACENA, 2013, p. 13).

Carvalho e Damacena descrevem "para fins didáticos, os desastres são constantemente descritos e classificados segundo suas causas como naturais (natural disasters) ou antropogênicos (man-made disasters). Os desastres naturais são aqueles decorrentes imediatamente de fenômenos naturais atribuíveis ao exterior do sistema social. [...] Já os desastres antropogênicos são constituídos por desastres tecnológicos e sociopolíticos e decorrem de fatores humanos" (CARVALHO; DAMACENA, 2013, p. 25).

Nesse diapasão, a fim de buscar mais uma definição para o que são desastres, o Centre for Research on the Epidemiology of Disasters (CRED) indica que desastre é "a situation or event, which overwhelms local capacity, necessitating a request to national or international level for external

\footnotetext{
${ }^{4}$ Desde a antiguidade até os tempos atuais, o ser humano vem sendo drasticamente marcado por grandes desastres. A estátua gigante de Rhodes fora destruída por um terremoto, em 224 antes de Cristo, o farol de Alexandria sobreviveu aos primeiros terremotos de 500 e 1182, mas sucumbiu ao de 1375 e assim por diante. Nessa época, o comum era que tais acontecimentos fossem considerados eventos controlados por Deus ou pelas estrelas (DAMACENA, 2012, p. 68).

${ }^{5} \mathrm{~A}$ história deste desastre indica uma evolução da teodiceia para a ciência natural, e mais tarde para a ciência social. De forma que o ocorrido em Lisboa alertou muitos cidadãos que antes eram submissos à aristocracia e suas noções de destino. Ainda, passaram a exigir mais dos governantes, e se investiram na qualidade de agentes de mudança do ambiente. "(...) o Marquês de Pombal mergulhou nos detalhes práticos de reconstrução e deu início a uma das primeiras investigações científicas sobre a mecânica de terremotos". Como consequência destes estudos, foram criados os primeiros códigos de edificação para eventos sísmicos (TYBUSCH, F. 2019, p. 173).
} 
assistance (...); an unforeseen and often sudden event that causes great damage, destruction and human suffering" ${ }^{6}$. (INTERNATIONAL FEDERATION OF RED CROSS AND RED CRESCENT SOCIETIES, 2011, [s.p.]).

De modo que, para que um desastre seja incluído no banco de dados, deve preencher ao menos um dos requisitos: Dez ou mais pessoas foram mortas no evento; 100 pessoas ou mais afetadas; Declaração de estado de emergência; Chamada para assistência internacional. O número de pessoas mortas inclui pessoas confirmadas como mortas e pessoas desaparecidas e supostamente mortas. As pessoas afetadas são aquelas que necessitam de assistência imediata durante um período de emergência (isto é, que requerem necessidades básicas de sobrevivência, como alimentos, água, abrigo, saneamento e assistência médica imediata). Os que estão referidos como feridos ou desabrigados são agregadas àquelas relatadas afetadas para produzir um "número total de pessoas afetadas". (INTERNATIONAL FEDERATION OF RED CROSS AND RED CRESCENT SOCIETIES, 2011, [s.p.]).

Desta forma, pode-se dizer também que o impacto econômico de um desastre geralmente consiste em consequências diretas na economia local (por exemplo, danos à infraestrutura, culturas, habitação) e consequências indiretas (por exemplo, perda de receita, desemprego, desestabilização do mercado). No EM-DAT, o valor registrado corresponde ao valor do dano no momento do evento e, geralmente, apenas para danos diretos, expresso em dólares americanos (valores de 2010). (INTERNATIONAL FEDERATION OF RED CROSS AND RED CRESCENT SOCIETIES, 2011). Diante do número crescente de vítimas da Covid-197, pode-se, neste primeiro momento, inseri-la como desastre.

$\mathrm{E}$, como foi abordado no tópico anterior, o surgimento de um novo vírus que deu origem à pandemia da Covid-19 modificou a normalidade do globo e impôs novas formas de se relacionar com o outro e com a natureza em suas mais diversas dimensões. Verifica-se também que epidemias podem ser caracterizadas como desastres, e no decorrer deste item, essa conceituação ficará ainda mais clara.

Doenças, particularmente as zoonoses e epidemias, de fato, estão cada vez mais frequentes. De acordo com uma entrevista realizada pelo Programa das Nações Unidas para o Meio Ambiente com o especialista ugandês Bernard Bett, "algumas das razões pelas quais elas estão mais frequentes são a crescente aproximação entre animais selvagens e humanos, a invasão de habitats naturais, a

\footnotetext{
${ }^{6}$ Tradução nossa: uma situação ou evento que supere a capacidade local, necessitando de um pedido a nível nacional ou internacional para assistência externa (...); um imprevisto e muitas vezes súbita que causa grande dano, destruição e sofrimento humano. (INTERNATIONAL FEDERATION OF RED CROSS AND RED CRESCENT SOCIETIES, 2011, [s.p.]).

${ }^{7}$ Até o fechamento da escrita deste artigo, o número de vítimas no Brasil ultrapassa o número de 390.797 e 14.340.787 de infectados, de acordo com o Painel Coronavírus (2020).
} 
urbanização e o desenvolvimento socioeconômico" (PNUMA, 2020). Registros indicam que de 1940 a 2004 houve um aumento na taxa de doenças infecciosas emergentes. "Dos 335 eventos documentados, $60,3 \%$ eram zoonóticos e $71,8 \%$ das zoonoses se originaram na vida selvagem" (UNEP, 2016, p. 22).

Assim, de acordo com artigo publicado na Revista Science,

Most of the factors that contribute to disease emergence will continue, if not intensify, in the 21st century. These include social factors (for example, lack of adequate health care and increases in international travel), demographic factors (for example, the aging of the population in developed countries, urbanization, and population growth), and environmental factors (for example, global climate change, lack of adequate sanitation, and land use practices that result in human contact with previously remote habitats), as well as microbial evolution. The public health community must develop long-term strategies to respond to these challenges12. (BINDER; LEVITT, 1999, p. 1312).

Nesse sentido, o que foi visualizado neste século XXI foi a emergência de doenças zoonóticas, assim como a associação, dentre vários outros fatores, da destruição da biodiversidade relacionada à disseminação de doenças e zoonoses (TYBUSCH, F.; OLIVEIRA, 2020, p. 54). Contudo, as chamadas doenças emergentes e aquelas com grande possibilidade de causar pandemias não são os únicos problemas das zoonoses ${ }^{8}$. Estas doenças negligenciadas são endêmicas e afetam com maior impacto as populações pobres, e junto a isso, estas doenças também recebem menos atenção internacional, governamental e financiamento. “A preocupação global concentra-se atualmente antraz, tuberculose bovina, brucelose, humanos africanostripanossomíase, cisticercose por Taena solium (tênia de porco), equinococose cística (hidatidose), leishmaniose e raiva (UNEP, 2016, p. 20).

Na Figura 1 a seguir, pode se ter uma ideia do impacto das zoonoses e dos seus tipos. Estas são ainda mais presentes onde existe desigualdade, proximidade de pessoas com animais, além do

\footnotetext{
${ }^{8}$ De acordo com a OMS, zoonose é: "A zoonosis is any disease or infection that is naturally transmissible from vertebrate animals to humans. Animals thus play an essential role in maintaining zoonotic infections in nature. Zoonoses may be bacterial, viral, or parasitic, or may involve unconventional agents. As well as being a public health problem, many of the major zoonotic diseases prevent the efficient production of food of animal origin and create obstacles to international trade in animal products". Tradução nossa: "Uma zoonose é qualquer doença ou infecção naturalmente transmissivel de animais vertebrados para seres humanos. Os animais, portanto, desempenham um papel essencial na manutenção de infecções zoonóticas na natureza. As zoonoses podem ser bacterianas, virais ou parasitárias ou podem envolver agentes não convencionais. Além de ser um problema de saúde pública, muitas das principais doenças zoonóticas impedem a produção eficiente de alimentos de origem animal e criam obstáculos ao comércio internacional de produtos de origem animal" (OMS, 2020).
} 
elemento "baixa resiliência". Estes fatores juntos fazem com que a magnitude de uma doença negligenciada seja sentida de forma muito mais latente nestas comunidades.

Figura 1. Impactos da Zoonose

\begin{tabular}{l|l|l}
\hline Zoonosis & $\begin{array}{l}\text { Primary transmission/ } \\
\text { reservoir species }\end{array}$ \\
\hline Avian Influenza & $\begin{array}{l}\text { The } 2004 \text { outbreak in East Asia resulted in economic losses of US\$ } \\
20 \text { billion over the following five years. }{ }^{48} \text { The } 2015 \text { outbreak in the } \\
\text { US has cost the poultry industry US\$ } 3.3 \text { billion and led to the death } \\
\text { of } 48 \text { million birds either from the flu itself or from culling. }\end{array}$ \\
\hline Bovine tuberculosis & $\begin{array}{l}\text { US\$ } 15 \text { billion of economic losses from } 1986-2009 \text { in the UK. } \\
\text { Ebola }\end{array}$ & $\begin{array}{l}\text { The } 2014-2015 \text { Ebola outbreak in Guinea, Liberia and Sierra Leone } \\
\text { led to } 11,310 \text { deaths and } 28,616 \text { confirmed cases. }{ }^{48}\end{array}$ \\
\hline MERS & $\begin{array}{l}\text { Since September } 2012,27 \text { countries have reported confirmed } \\
\text { cases, with about } 624 \text { deaths. }{ }^{49}\end{array}$ \\
\hline Nipah virus & $\begin{array}{l}\text { US } \$ 671 \text { million of economic losses, one million pigs culled, and } \\
100 \text { people died from the } 1998 \text { outbreak in Malaysia. }\end{array}$ \\
\hline SARS & $\begin{array}{l}\text { The impact of the } 2002 \text { outbreak was estimated at US\$ } 41.5 \text { billion, }^{7} \\
\text { with } 8,000 \text { confirmed infections and } 800 \text { deaths. }\end{array}$ \\
\hline
\end{tabular}

Fonte (UNEP, 2016, p. 21).

O que vai ao encontro do pensamento de Ulrich Beck $(2006$, p. 6) em entrevista para o IHU Unisinos em que indica os "riscos globais são por si só desigualmente distribuídos". Eles se desdobram de diferentes maneiras em cada contexto concreto, mediados por históricos diferentes e padrões culturais e políticos". Ou seja, os riscos não são distribuídos igualmente, ao contrário, são percebidos de forma diferente, de acordo com a situação e vulnerabilidade de cada local.

Mais um ponto, a vulnerabilidade é um elemento que merece atenção. Para Verchick (2017, p. 72), o direito deveria dar mais atenção a vulnerabilidade social, pois, "os desastres retratam as

\footnotetext{
${ }^{9}$ No livro intitulado "Sociedade do Risco" de Ulrich Beck (2011), o autor tem pensamento contrário a entrevista realizada em 2006. Indica na obra que, "há um padrão de distribuição dos riscos no qual se encontra um material politicamente explosivo: cedo ou tarde, eles alcançam inclusive aqueles que os produziram ou que lucraram com eles. Em sua disseminação, os riscos apresentam socialmente um efeito bumerangue: nem os ricos e poderosos estão seguros diante deles". (BECK, 2011, p. 44).
} 
vulnerabilidades". Ou melhor, os desastres ressaltam e acentuam as vulnerabilidades. De forma que, seu impacto e magnitude não são determinados pelo tipo de evento (climatológico, industrial ou híbrido), mas pela situação e grau de vulnerabilidade do local que é impactado pelo evento, de acordo com Carvalho e Damacena (2013, p. 17).

Essa vulnerabilidade é extremamente relevante, tenha ela contornos sociais ou ecológicos. O primeiro caso é profundamente complexo e aparece de forma transparente em países mais pobres, material e culturalmente, onde, em geral, as instituições políticas são deficientes e não funcionais. O segundo tipo de vulnerabilidade (ecológica) está ligado à exposição das cidades, estados ou países a riscos desnecessários, por desconsideração ou despreocupação com a preservação das infraestruturas naturais, gratuitamente dadas e com função específica de proteção (corais, dunas, matas ciliares, mangues, áreas de preservação permanente, topos de morro) (CARVALHO; DAMACENA, 2013, p. 17).

A exemplo da Covid-19, o Conselho Nacional de Saúde (CNS),

reforçou às autoridades brasileiras a necessidade de proteger contra os impactos da COVID-19 principalmente os grupos em situação de vulnerabilidade ou em risco, como pessoas em situação de rua, com sofrimento ou transtorno mental, com deficiência, vivendo com HIV/aids, LGBTI+, população indígena, negra e ribeirinha e trabalhadores do mercado informal, como catadores de lixo, artesãos, camelôs e prostitutas (STEVANIN, 2020, [s.p]).

Nesse sentido, estudos revelam o perfil dos primeiros infectados no Brasil. No início, existia uma associação entre taxa de teste e renda per capita, revelando uma disparidade socioeconômica ${ }^{10}$ cada vez maior na prática de casos se expande (SOUZA et al., 2020). Assim, em um primeiro momento, a doença ficou irrestrita a classes mais altas, e no final de março houve a transição, e o vírus passa a atingir camadas mais vulneráveis.

\footnotetext{
${ }^{10}$ De acordo com o Boletim Socioepidemiológico da Covid-19 nas Favelas: "O boletim revela que apesar da ausência de preenchimento da variável raça/cor em $45 \%$ das notificações (22.416), a ocorrência da covid-19 é maior na população negra nos bairros classificados como "concentração altíssima", "concentração alta" e "concentração mediana" de áreas cobertas por favelas. Nos bairros de "concentração baixa", o percentual da população negra $(25,6 \%)$ é muito próximo a ocorrência na população branca $(27,6 \%)$. Com relação ao gênero, em todas as tipologias urbanas, as maiores taxas de mortalidade são do sexo masculino. Nos bairros com "altíssima concentração de favelas", o valor da taxa de mortalidade entre os homens é de, aproximadamente, 6 a cada 10 mil habitantes do sexo masculino, enquanto nos "bairros sem favelas" chega a quase 14 por 10 mil habitantes. A taxa de letalidade apresentou padrão similar, sendo maior que a do sexo feminino em todas as tipologias urbanas. (FIOCRUZ, 2020).
} 
O Centers for Disease Control and Prevention (CDC, 2020) indica 5 elementos determinantes que colocam os grupos minoritários raciais e étnicos em maior risco de adoecer e morrer de Covid-19, dentro destes elementos estão: a discriminação; o acesso e utilização de serviços e saúde; ocupação; Lacunas educacionais, de renda e de riqueza; e, a habitação. Desta forma, estes elementos podem contribuir para taxas mais altas de hospitalizações e mortes pelo vírus. Pois, as estratégias para possibilitar a disseminação da doença afetaram e causaram danos não intencionais como desemprego e acesso reduzido a serviços, dentre muitos outros incidindo diretamente sobre as populações mais vulneráveis.

De acordo com o relatório da Oxfam (2020, p. 5),

A trajetória do vírus é uma fotografia das profundas desigualdades do país. Antes da Covid19, o Brasil tinha 40 milhões de trabalhadores informais e 11,9 milhões de desempregados, muitos sem proteção social. As expectativas apontam que o desemprego pós-pandemia pode aumentar para taxas de $15 \%$, com 16 milhões de desempregados. Ao redor de 5 milhões de moradias estão localizadas em favelas, em grande parte sem acesso a água tratada e saneamento básico e com alta densidade de pessoas por residência. $E$ isso quando a higienização e o distanciamento social são essenciais para evitar a propagação do vírus. A essas cifras se soma o racismo estrutural do país onde $75 \%$ dos mais pobres são pessoas negras (pretos e pardos, por definição do IBGE). Não surpreende que os números mostrem que as pessoas negras e pobres correspondam ao perfil de vítima mais comum da Covid-19 no Brasil, representando 6 de cada 10 mortes.

Destarte, quanto maior for a vulnerabilidade, maior serão as consequências do desastre. $E$, o Brasil se encontra como um dos países que mais possui números de infectados e de vítimas por dia ${ }^{11}$, o que ressalta e corrobora com todas as informações e dados que já foram demonstrados, de que existe uma grande desigualdade em nosso território, e somada a isso, um descaso e uma falta de organização para o combate a disseminação do vírus por parte do governo ${ }^{12}$.

Uma outra análise, para configurar a Covid-19 como um desastre, foi realizada por Carvalho (2020, [s.p.]) na qual, para defini-la como desastre biológico (terminologia utilizada pelo autor) seria

\footnotetext{
${ }^{11}$ De acordo com dados da OMS publicizados pela Estadão (2020): “O Brasil supera o EUA e Reino Unido e é o primeiro do mundo na média diária de mortes pelo coronavírus. No dia 06 de abril de 2021, o Brasil alcançou a triste marca de 4 mil mortes por Covid registradas em um dia pela 1a vez $(G 1,2021)$.

12 O Brasil está a mais de dois meses sem titular à frente do Ministério da Saúde (SOUZA; FERREIRA, 2020). Também, o Conselho Nacional de Saúde, em matéria "Em resposta ao descaso do governo, organizações lançam Plano Nacional de Enfrentamento à Covid-19" elaboraram o Plano Nacional de Enfrentamento à Covid-19 devido à ausência de um planejamento de Estado para lidar com a crise sanitária, acentuando as consequências para a população. Nesse sentido, para suprir essa lacuna, organizações do campo da saúde e da sociedade civil, que integram a Frente Pela Vida, entre elas o Conselho Nacional de Saúde (CNS) organizaram o Plano (CNS, 2020).
} 
necessário a visualização de 3 elementos: “(i) causas e (ii) consequências altamente específicas e complexas, convergindo para a descrição de fenômenos socioambientais de grande apelo midiático e irradiação econômica, política, jurídica e ambiental, capazes de comprometer a (iii) estabilidade do sistema social". Assim, o autor indica as "causas", sendo elas de ordem biológica, e como abordado anteriormente neste artigo, se integra ao conceito de desastre.

No segundo ponto, "consequências complexas e específicas", tem-se um número considerável de vítimas, o que, de acordo com o Centre for Research on the Epidemiology of Disasters, já se demonstra como desastre pois, o número de vítimas é maior do que 10, mais de 100 pessoas foram afetadas e houve a decretação de estado de emergência em diversas cidades, estados e países. Por fim, a "estabilidade do sistema social", os desastres são extremamente complexos e as suas causas podem ser diversas, o que ocasionou, no caso da Covid-19, a instabilidade de vários estados e municípios, decretando Situação de Emergência (BRASIL, 2020a) ou de Estado de Calamidade Pública (BRASIL, 2020b). Assim, com a finalidade de se pensar em uma gestão de riscos aplicável a Covid-19, é importante mencionar a gestão socioambiental do risco, uma versão adaptada do ciclo de gestão dos desastres do professor estadunidense, Daniel Farber (2012).

A gestão socioambiental do risco (TYBUSCH, F. 2019) é composta por algumas fases: mitigação, resposta de emergência, compensação e reconstrução. Ter planos bem definidos e trabalhar na organização de prevenção de danos é essencial para não se ter ou se amenizar os resultados de um desastre. No entanto, o que se percebe no cenário brasileiro, são falhas já na primeira fase do ciclo de gestão socioambiental do risco, na mitigação. Um dos problemas, foi chamado pela Organização Mundial da Saúde, de infodemia ${ }^{13}$.

Assim, em paralelo a busca por produção de vacinas e a vacinação, existe uma outra "doença" que se expande em campos menos convencionais, os discursos. Este combate às informações falsas, as denominadas fake news, têm se desenvolvido em um cenário de medos e incertezas, e muitas vezes totalmente desvinculado do comportamento sugerido pela ciência. Assim, na crise provocada pela Covid-19 informações e dados falsos ou sem comprovação científica tem gerado equívocos e tensionamentos entre a ciência e o Estado, como exemplos: tratamentos preventivos, utilização de máscara e distanciamento social (HENRIQUES; VASCONCELLOS, 2020).

\footnotetext{
${ }^{13}$ De acordo com a OPAS (2020, p. 01) infodemia é: "um grande aumento no volume de informações associadas a um assunto específico, que podem se multiplicar exponencialmente em pouco tempo devido a um evento específico, como a pandemia atual.
} 
Resta claro que, a informação é importantíssima para a prevenção dessa doença de magnitude e consequências ainda incomensuráveis. Assim, a Teoria dos Desastres pode ser possibilidade para além da utilização da terminologia, empregada também com a finalidade de buscar planos e estratégias de prevenção e controle contra a disseminação do vírus.

\section{CONCLUSÃO}

A história da "Arca de Noé" foi ressignificada e utilizada como analogia pelos autores no decorrer da escrita deste artigo. Ficou demonstrado que "não estamos no mesmo barco", no sentido de que as consequências e os impactos ocasionados pela doença da Covid-19 são sentidos de forma não equânime pela população, principalmente por populações vulneráveis.

Aliás, o elemento vulnerabilidade, abordado nos itens supracitados, é fator importante para determinar a magnitude do evento desastre. Quanto maior for a vulnerabilidade, maiores serão os impactos sentidos na sociedade, na saúde e na economia. Assim, a seleção de quem entrará no "barco" perpassa também por critérios de ordem socioeconômica, ou seja, quanto melhor for a condição social, menos riscos o indivíduo terá de ser contaminado, e caso seja, será portador de recursos para alcançar um tratamento e acesso aos hospitais.

A necessidade de categorizar a Covid-19 como um desastre surge diante da situação de caos e de emergência instaurada no globo. Milhares de pessoas foram vítimas da doença, outros milhares foram infectados, e os números ainda se encontram em crescimento. Ao redor do mundo, fronteiras foram fechadas e estratégias para conter esta pandemia sem precedentes foram colocadas em prática.

No entanto, alguns países desconsideraram as medidas provenientes da Organização Mundial da Saúde (OMS), retardando ações e medidas de prevenção, ocasionando o perceptível resultado na atualidade, localizando esses no ranking dos países com o maior número de vítimas e de infectados, incluso o Brasil. O que difere o Brasil dos demais países que integram o ranking é o cenário de desigualdade e de vulnerabilidade em que se encontra a maior parte da população brasileira. Por isso, a Covid-19 impacta de forma diferente cada local, e suas consequências também são diferentes em cada região. Nesse sentido, considerando que os desastres atingem sistemicamente a sociedade, o presente artigo buscou o estudo da Teoria do Direito dos Desastres, trazendo como problema central, a análise sobre as possibilidades de aplicação desta Teoria à pandemia ocasionada pelo coronavírus. 
Visto que desastres como a pandemia são estruturados pela dinâmica da sociedade do risco, a partir da lógica desenvolvimentista estabelecida pela hegemonia do Norte Social, impactando severamente o ambiente e revelando danos de ordem socioeconômica, incluindo o aumento da vulnerabilidade socioambiental, demonstrando que quanto mais vulnerável for uma comunidade, maior será a produção de risco e menor a capacidade de prevenção e de superação de paradigmas de crise. Esta sociedade, portanto, aponta para saídas através de uma compreensão sistêmico-complexa e, principalmente, de que são os mais pobres carecedores da presença do Estado, provendo-Ihes os mínimos direitos básicos, além de alertar para a tentativa de superação do sistema atual vigente, degradante ambiental e socialmente, para que, em situações de desastre, se possam ver alternativas, prevenção e diminuição da vulnerabilidade socioambiental.

Por fim, a partir da definição de que a Covid-19 é um desastre biológico, foram levantadas diversas fontes que demonstravam o caráter de desastre dessa doença. Por ser o desastre da Covid19 de ordem biológica, como foi demonstrado, por ter um número significativo de vítimas, de afetados e da situação de emergência ter sido decretada; por serem os desastres complexos e as suas causas diversas; pela instabilidade que gera ao sistema, levando estados e municípios a decretar estado de calamidade pública; é que se ressalta a possibilidade de utilização da terminologia "desastres biológicos" na busca de alternativas e estratégias de prevenção baseadas na Teoria do Direito dos Desastres.

\section{REFERÊNCIAS}

BECK, Ulrich. Sociedade do Risco: rumo a uma outra modernidade. São Paulo: Ed 34, 2010.

BRASIL. Lei № 13.979, de 6 de fevereiro de 2020. Dispõe sobre as medidas para enfrentamento da emergência de saúde pública de importância internacional decorrente do coronavírus responsável pelo surto de 2019. Disponível em: http://www.in.gov.br/en/web/dou/-/lei-n-13.979-de-6-defevereiro-de-2020-242078735. Acesso em: 26 abr. 2021.

BRASIL. Decreto Legislativo no 6, de 2020. Reconhece, para os fins do art. 65 da Lei Complementar no 101 , de 4 de maio de 2000, a ocorrência do estado de calamidade pública, nos termos da solicitação do Presidente da República encaminhada por meio da Mensagem no 93, de 18 de março de 2020. Disponível em: http://www.planalto.gov.br/ccivil_03/portaria/DLG6-2020.htm._Acesso em: 26 abr. 2021.

CDC. Centers for Disease Control and Prevention. Health Equity Considerations and Racial and Ethnic Minority Groups. Disponível em: https://www.cdc.gov/coronavirus/2019ncov/community/health-equity/race-ethnicity.html Acesso em: 26 abr. 2021. 
CAPRA, Fritjof. As conexões ocultas - ciência para uma vida sustentável. São Paulo: Cultrix, 2002.

CAPRA, Fritjof. A teia da vida: uma nova compreensão científica dos sistemas vivos. Trad. Newton Roberval Eichmberg. São Paulo: Cultrix, 2012.

CARVALHO, Délton Winter de; DAMACENA, Fernanda Dalla Libera. Direito dos Desastres. Porto Alegre: Livraria do Advogado, 2013.

CARVALHO, Délton Winter de. A natureza jurídica da pandemia da COVID-19 como um desastre biológico. Conjur. Disponível em: https://www.conjur.com.br/2020-abr-21/direito-pos-graduacaonatureza-juridica-pandemia-COVID-19-desastre-biologico. Acesso em: 26 abr. 2021.

CNS. Conselho Nacional de Saúde. Ministério da Saúde. Em resposta ao descaso do governo, organizações lançam Plano Nacional de Enfrentamento à COVID-19. Disponível em: http://conselho.saude.gov.br/ultimas-noticias-cns/1258-em-resposta-ao-descaso-do-governoorganizacoes-lancam-plano-nacional-de-enfrentamento-a-COVID-19. Acesso em: 26 abr. 2021. CORONAVÍRUS BRASIL. Painel Coronavírus. Disponível em: https://covid.saude.gov.br/ Acesso em: 26 abr. 2021.

DAMACENA, Fernanda Dalla Libera. A formação sistêmica de um direito dos desastres. Dissertação (mestrado) Universidade do Vale do Rio dos Sinos, Programa de Pós-Graduação em Direito, São Leopoldo, RS, 2012.

FARBER, Daniel. Disaster law and emerging issues in Brazil. Revista de Estudos Constitucionais, Hermenêutica e Teoria do Direito (RECHTD) 4(1): 2-15 janeiro-junho 2012.Disponível em: http://www.revistas.unisinos.br/index.php/RECHTD/article/view/rechtd.2012.41.01/932 Acesso em: 26 abr. 2021.

FIOCRUZ. Boletim Socioepidemiológico da COVID-19 nas Favelas: Análise da incidência, frequência, mortalidade e letalidade por COVID-19 em favelas cariocas. Disponível em: https://portal.fiocruz.br/sites/portal.fiocruz.br/files/documentos/boletim_socioepidemiologicos_cov id_nas_favelas_1.pdf. Acesso em: 26 abr. 2021.

FREITAS, Carlos Machado de; CARVALHO, Mauren Lopes de; XIMENES, Elisa Francioli; ARRAES, Eduardo Fonseca; GOMES, José Orlando. Vulnerabilidade socioambiental, redução de riscos de desastres e construção da resiliência - lições do terremoto no Haiti e das chuvas fortes na Região Serrana, Brasil. Ciência \& Saúde Coletiva, v. 17, n. 6, p. 1577-1586, 2012. Disponível em: https://www.scielosp.org/pdf/csc/2012.v17n6/1577-1586/pt. Acesso em: 26 abr. 2021.

FREITAS, Juarez. Sustentabilidade: Direito ao futuro. 2. ed. Belo Horizonte: Fórum, 2012.

GABRIEL, Markus. El virus, el sistema letal y algunas pistas. Trad. Lucas Antón. Sopa de Wuhan pensamiento contemporáneo en tiempos de pandemias. 1. ed. ASPO, 2020.

GALINDO, Maria. Desobediencia, por tu culpa voy a sobrevivir. Trad. Lucas Antón. Sopa de Wuhan pensamiento contemporáneo en tiempos de pandemias. 1. ed. ASPO, 2020. 
GALHARDO, Ricardo. O Brasil supera o EUA e Reino Unido e é o primeiro do mundo na média diária de mortes pelo coronavírus. Estadão. Disponível em:

https://saude.estadao.com.br/noticias/geral,brasil-supera-eua-e-reino-unido-e-e-o-primeiro-domundo-na-media-diaria-de-mortes-pelo-coronavirus,70003330090 Acesso em: 26 abr. 2021.

GIDDENS, Anthony. Mundo em descontrole. Trad. Maria Luiza X. de A. Borges. 3. ed. Rio de Janeiro: Record, 2003.

HAN, Byung-Chul. La emergencia viral y el mundo de mañana. Trad. Lucas Antón. Sopa de Wuhan pensamiento contemporáneo en tiempos de pandemias. 1. ed. ASPO, 2020. p. 97-111.

HARVEY, David. Política anticapitalista en tiempos de COVID-19. Trad. Lucas Antón. Sopa de Wuhan pensamiento contemporáneo en tiempos de pandemias. 1. ed. ASPO, 2020. p. 79-96.

HENRIQUES, Cláudio Maierovitch Pessanha; VASCONCELOS, Wagner. Crises dentro da crise: respostas, incertezas e desencontros no combate à pandemia da Covid-19 no Brasil. Estudos Avançados, v. 34, n. 99, São Paulo, May/Aug. 2020, Epub July 10, 2020. Disponível em: https://www.scielo.br/scielo.php?script=sci_arttext\&pid=S0103-40142020000200025 Acesso em: 26 abr. 2021.

IHU UNISINOS. Sociedade do Risco: Medo na Modernidade. Disponível em: http://www.ihuonline.unisinos.br/media/pdf/IHUOnlineEdicao181.pdf. Acesso em: 26 abr. 2021.

INTERNATIONAL FEDERATION OF RED CROSS AND RED CRESCENT SOCIETIES. World Disasters Report: Focus on Hunger and malnutrition. 2011. Disponível em: https://www.ifrc.org/PageFiles/99868/Photos/wdr.pdf Acesso em: 26 abr. 2021.

JONES, Kate E.; PATEL, Nikkita G.; LEVY, Marc A. et al. Global trends in emerging infectious diseases. Nature. Vol 451, 21 February, 2008. Disponível em: https://www.nature.com/articles/nature06536 Acesso em: 26 abr. 2021.

KREPS, Gary A. Disaster, Sociology. In: SMELSER, N.J.; BATES, Paul B. (eds.) International Encyclopedia of the Social and Behavioral Sciences. Amsterdam: Elsevier Publishing Company, 2001.

MINISTÉRIO DA SAÚDE. Coronavírus COVID-19. 2020. Disponível em:

https://coronavirus.saude.gov.br/. Acesso em: 26 abr. 2021.

MORIN, Edgar. Introdução ao pensamento complexo. Trad. Dulce Matos. 4.ed. Lisboa: Instituto Piaget, 2003.

OMS. Organização Mundial da Saúde. Zoonoses. Disponível em: http://www.who.int/topics/zoonoses/en/. Acesso em: 26 abr. 2021.

ORGANIZAÇÃO PAN-AMERICANA DA SAÚDE - OPAS. Organização Mundial da Saúde - OMS. Repositório Institucional para Troca de Informações - Iris. Fichas Informativas COVID-19: entenda a infodemia e a desinformação na luta contra a COVID-19 [Internet]. Brasília: Organização Pan- 
Americana da Saúde; 2020 [citado 2020 ago 3]. Disponível em:

https://iris.paho.org/handle/10665.2/52054?locale-attribute=pt» Acesso em: 26 abr. 2021.

OXFAM. QUEM PAGA A CONTA? Taxar a riqueza para enfrentar a crise da COVID-19 na América Latina e Caribe Disponível em: https://rdstation-

static.s3.amazonaws.com/cms/files/115321/1595622094Nota_informativa_da_Oxfam_Quem_Paga_ a_Conta.pdf. Acesso em: 26 abr. 2021.

SACHS, Ignacy. Caminhos para o desenvolvimento sustentável. Rio de Janeiro: Garamond, 2002.

SANTOS, Boaventura de Sousa. A cruel pedagogia do vírus. Coimbra: Almedina, 2020.

SANTOS, Boaventura de Sousa; ARAÚJO, Sara; BAUMGARTEN, Maíra. As Epistemologias do Sul num mundo fora do mapa. Sociologias, v. 18, n. 43, Porto Alegre, p. 14-23, set. /dez. 2016. Disponível em: https://www.scielo.br/pdf/soc/v18n43/1517-4522-soc-18-43-00014.pdf. Acesso em: 26 abr. 2021.

SANTOS, Boaventura de Sousa. Para Além do Pensamento Abissal: das linhas globais a uma ecologia de saberes. In: SANTOS, Boaventura de Sousa; MENESES, Maria Paula (Org.). Epistemologias do Sul. São Paulo: Cortez, 2010. p. 31-83.

SANTOS, Boaventura de Sousa; MENESES, Maria Paula. G.; NUNES, João Arriscado. Introdução: Para ampliar o cânone da ciência: a diversidade epistemológica do mundo. In: SANTOS, Boaventura de Sousa. (Org.). Semear outras Soluções: os caminhos da biodiversidade e dos conhecimentos rivais. Rio de Janeiro: Civilização Brasileira, 2010.

SOUZA, André de; FERREIRA, Paula. Brasil completa dois meses sem titular à frente do Ministério da Saúde. O Globo. Disponível em: https://oglobo.globo.com/sociedade/brasil-completa-dois-mesessem-titular-frente-do-ministerio-da-saude-1-24533078 Acesso em: 26 abr. 2021.

SOUZA, William. Epidemiological and clinical characteristics of the early phase of the COVID-19 epidemic in Brazil. Medrxiv, Yale. Disponível em:

https://www.medrxiv.org/content/10.1101/2020.04.25.20077396v1.full.pdf. Acesso em: 26 abr. 2021.

STEVANIN, Luiz Felipe. Vulnerabilidades que aproximam: Das aldeias às ruas, medidas contra a COVID-19 esbarram em realidades marcadas pela desigualdade e na ausência de direitos básicos, como saúde, emprego e moradia. RADIS, n. 212, p. 10-15, 2020. Disponível em:

https://radis.ensp.fiocruz.br/phocadownload/revista/Radis212_web.pdf. Acesso em: 26 abr. 2021.

TYBUSCH, Jerônimo Siqueira. Sustentabilidade multidimensional como ação reflexiva para uma ecologia política pós-colonial. In: ESTENSSORO, Fernando et al (Org.). América Latina e Caribe na encruzilhada ambiental: dimensões política, jurídica e estratégica. ljuí: Unijuí, 2011.

TYBUSCH, Francielle Benini Agne. Vidas deslocadas: O caso Mariana-MG como modelo brasileiro para aplicação do Direito dos Desastres. 1. ed. Curitiba: Íthala, 2019. 
TYBUSCH, Francielle Benini Agne; OLIVEIRA, Gislaine Ferreira. A crise da biodiversidade e seus impactos no surgimento de pandemias: uma análise sobre o desastre biológico da covid-19. In: CALGARO, Cleide; REZENDE, Elcio Nacur Rezende; TYBUSCH, Jerônimo Siqueira (Coord.) Direito e sustentabilidade I [Recurso eletrônico on-line] Florianópolis: CONPEDI, 2020. Disponível em: http://conpedi.danilolr.info/publicacoes/nl6180k3/nk9s678I/nEYM56d4Ch360g7f.pdf Acesso em: 26 abr. 2021.

UNEP. UNEP Frontiers 2016 Report: Emerging Issues of Environmental Concern. United Nations Environment Programme, Nairobi. Disponível em:

https://environmentlive.unep.org/media/docs/assessments/UNEP_Frontiers_2016_report_emerging _issues_of_environmental_concern.pdf. Acesso em: 26 abr. 2021.

VERCHICK, Robert R. M. (IN)Justiça dos desastres: a geografia da capacidade humana. In: FARBER, Daniel. A.; CARVALHO, Délton. W. (Org.). Estudos Aprofundados em Direito dos Desastres: Interfaces Comparadas. Curitiba: Prismas, 2017.

ZIBECHI, Raúl. A las puertas de un nuevo orden mundial. Trad. Lucas Antón. Sopa de Wuhan pensamiento contemporáneo en tiempos de pandemias. 1. ed. ASPO, 2020. p. 113-118.

WALKER, Patrick GT; WHITTAKER, Charles; WATSON, Oliver et al. The Global Impact of COVID-19 and Strategies for Mitigation and Suppression. London: Imperial College London, 2020. Disponível em: https://www.cos.ufrj.br/arquivos/COVID19/Imperial-College-COVID19-Global-Impact-26-032020.pdf. Acesso em: 26 abr. 2021.

Sobre os autores:

\section{Francielle Benini Agne Tybusch}

Doutora em Direito pela Universidade do Vale do Rio dos Sinos - UNISINOS. Mestre em Direito pela Universidade Federal de Santa Maria - UFSM com bolsa da Fundação de Amparo à Pesquisa do Estado do Rio Grande do Sul, FAPERGS. Bacharel em Direito pela Faculdade Palotina de Santa Maria - FAPAS. Professora do Curso de Direito da Universidade Franciscana - UFN. Coordenadora do Laboratório de Extensão da Universidade Franciscana UFN. Professora Substituta do Departamento de Direito da Universidade Federal de Santa Maria - UFSM. Membro da equipe técnica da Revista Direitos Emergentes na Sociedade Global da Universidade Federal de Santa Maria. Integrante do Grupo de Pesquisa em Direito da Sociobiodiversidade (GPDS) da Universidade Federal de Santa Maria - UFSM e e do Grupo de Pesquisa em Direito, Risco e Ecocomplexidade da Universidade do Vale do Rio dos Sinos - UNISINOS. Autora do livro "Vidas Deslocadas: O caso Mariana - MG como modelo de aplicação para o Direito dos Desastres" lançado pela Editora Íthala. Universidade Federal de Santa Maria (UFSM), Santa Maria, RS, Brasil

Lattes: http://lattes.cnpq.br/4400702817251869 Orcid: https://orcid.org/0000-0001-6158-399X

E-mail:francielleagne@gmail.com

\section{Jerônimo Siqueira Tybusch}

Doutor em Ciências Humanas pela Universidade Federal de Santa Catarina - UFSC (2011); mestre em Direito Público pela Universidade do Vale do Rio dos Sinos - UNISINOS (2007); graduado em Direito pela Universidade de Santa Cruz do Sul - UNISC (2004). Professor Adjunto no Departamento de Direito da Universidade Federal de Santa Maria - UFSM. Professor do Programa de Pós-Graduação em Direito (PPGD/UFSM) - Mestrado em Direito.

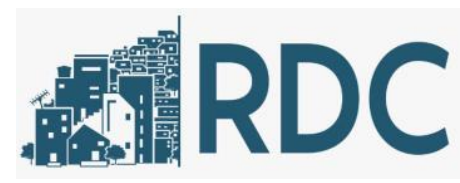

Rev. Dir. Cid., Rio de Janeiro, Vol. 14, N.01., 2022, p. 170-193.

Francielle Benini Agne Tybusch, Jerônimo Siqueira Tybusch e Francieli lung Izolani

DOI: $10.12957 /$ rdc.2022.54314| ISSN 2317-7721 
Professor do Programa de Pós-Graduação em Tecnologias Educacionais em Rede (PPGTER/UFSM) - Mestrado Profissional em Tecnologias Educacionais em Rede. Pesquisador e Líder do Grupo de Pesquisa em Direito da Sociobiodiversidade - GPDS. Atualmente é Pró-Reitor Adjunto e Coordenador de Planejamento Acadêmico da Pró-Reitoria de Graduação da UFSM. Membro da Diretoria do CONPEDI Gestão 2017-2020. Desenvolve pesquisas nas áreas de: Direito Ambiental; Ecologia Política; Direito e Sustentabilidade; Direito Urbanístico; Teoria do Direito e da Decisão Jurídica; Direito e Novas Tecnologias; Tecnologias Educacionais em Rede. Universidade Federal de Santa Maria (UFSM), Santa Maria, RS, Brasil

Lattes: http://lattes.cnpq.br/6477064173761427 Orcid: https://orcid.org/0000-0001-8238-7453

E-mail:eronimotybusch@ufsm.br

\section{Francieli lung Izolani}

Pesquisadora Capes (Código 001). Graduada em Direito pela Universidade Regional do Noroeste do Estado do Rio Grande do Sul (2008). Aprovada no 3/2008 Exame da Ordem dos Advogados do Brasil (OAB). Pós-Graduada em Direito Previdenciário com ênfase ao Magistério Superior pela Universidade Anhanguera-Uniderp (2011), Pós-Graduada em Direito Constitucional pela Universidade Anhanguera-Uniderp (2016) e Pós-Graduada em Direito Civil pela Universidade Anhanguera-Uniderp (2016). Mestranda em Direito pela Universidade Federal de Santa Maria (2019 - em andamento). Integrante do Grupo de Pesquisa em Direito da Sociobiodiversidade (GPDS) da Universidade Federal de Santa Maria (UFSM). Membro da equipe técnica da Revista Direitos Emergentes na Sociedade Global da Universidade Federal de Santa Maria (UFSM). Coordenadora da Coleção Latinoamérica y Derecho en Exposición. Coordenadora da Coleção Derecho Civil en Foco. Curso de língua italiana pelo Idiomas Sem Fronteiras (2019 - nível A1). Curso de língua espanhola pelo Instituto Cervantes (2013- Nível B2). Curso de língua inglesa pelo Centro de Ensino Fisk (1998-2003) com Proficiência e Aprovação no Toefl Exam (2005). Curso de informática pela Maffia (1997). Universidade Federal de Santa Maria (UFSM), Santa Maria, RS, Brasil Lattes: http://lattes.cnpq.br/9027530784430798 Orcid: https://orcid.org/0000-0002-1307-7758

E-mail:franizolani@hotmail.com

\section{Os autores contribuíram igualmente para a redação do artigo.}

